\title{
Impact of Covid-19 Pandemic on the Treatment of Cancer Patients Registered at a Tertiary Care Centre in Eastern India
}

\author{
Arnab Kumar Ghosh, Bappaditya Chhatui, Bhukya Swetha, Anis Bandyopadhyay, \\ Niladri Roy, Abhishek Basu, Alakananda Choudhury, Janmenjoy Mondal
}

Department of Radiotherapy, Medical College and Hospital, Kolkata, India.

\begin{abstract}
Background: Cancer care has suffered during the covid-19 pandemic due to diversion of manpower to treat covid patients and introduction of lockdown measures. Delay in treatment is detrimental to cancer patients. During the national lockdown, many patients were not able to visit our treatment facility. We conducted this study to evaluate the detriment caused by the pandemic on cancer care in terms of disease progression and the socio economic factors associated with delay in presentation. Materials and Methods: Patients visiting our OPD who were being treated at our department and could not visit the facility during the lockdown were selected. Present status of the disease was assessed using clinical examination and radiological tests. Psycho social distress was assessed using PO BADO SF questionnaire. Disease progression, cause of delay was assessed against various factors like per capita family income, cost of transportation etc. Appropriate statistics was used to analyse and represent the data. Results: $50 \%$ patients had disease progression. "High cost of transportation" was the most common response given by patients for not visiting the treatment facility during the lockdown. Most patients being treated with radiotherapy $(69 \%)$ had responded either "high cost of transportation" or "lack of proper accommodation" as cause of delay ( $p$ 0.065). Patients with treatment gap of 80 days or more had higher per capita family income, higher cost of transportation during the lockdown and larger distance between residence and treatment facility. $77.5 \%$ patients had psycho social distress according to assessment by PO BADO SF questionnaire. Conclusion: COVID 19 pandemic control measures have impacted cancer care in resulting in disease progression, treatment delays and psycho-social distress. A number of factors may have contributed to the treatment delays like high cost of transportation during the lockdown, longer distance between residence and hospital.
\end{abstract}

Keywords: Covid 19- cancer- radiotherapy- psycho social distress

Asian Pac J Cancer Care, 6 (Supp I), 11-16

\section{Introduction}

COVID 19 disease caused by Severe Acute Respiratory Syndrome Coronavirus 2 ( SARS-COV 2) has been declared as a global pandemic by WHO on $11^{\text {th }}$ March 2020 [1]. Emerging from China, the virus has infected millions of patients, taking a toll on global economy and healthcare [2-4]. India saw its first corona virus case on $30^{\text {th }}$ January 2020 in Kerala (WHO India Situation Update Report 1), however as of $12^{\text {th }}$ July 2020, India has seen 849553 confirmed cases which is the highest in Asia (WHO India Situation Update Report 24) [5] .

India has a high incidence of cancer patients with
Submission Date: 12/17/2020Ａcceptance Date: 02/13/2021

Corresponding Author:

Dr. Bhukya Swetha

Department of Radiotherapy, Medical College and Hospital, Kolkata, India.

Email: swethab2119@gmail.com 
SARS-COV 2 on visiting the treatment facility are major concerns of cancer treatment in the pandemic situation. However, the patients who are already being treated with chemotherapy/radiotherapy are at major risk of disease progression and treatment failure due to accelerated repopulation of cancer cells on abrupt discontinuation of treatment [10].

Our institute provides a comprehensive cancer care involving the department of radiation oncology, medical oncology, surgical oncology and onco-pathology. Major decisions are taken by the multimodality tumour board involving all major departments in the decision making. The centre caters to the treatment needs of multiple districts in the state. During the national lockdown, the radiation oncology department had a major decrease in number of new registrations and patients under treatment. In the month of June with ease of lockdown measures and gradual increase in OPD attendance, a number of patients had presented with symptoms and signs of progressive disease. So we conducted this study to evaluate the detriment caused by the pandemic on cancer care in terms of disease progression and the socio economic factors associated with delay in presentation. As a secondary objective, we wanted to assess the distress in cancer patients on getting treated at our centre which is dedicated to treating patients with SARS-COV 2 infection.

\section{Materials and Methods}

\section{Patient Selection}

Patients visiting the out-patient department (OPD) of the department of Radiation Oncology in June 2020 were taken for the study. Patients who were previously registered and were being treated with a curative or palliative intent with radiotherapy, chemotherapy and other modality, did not visit the treatment facility during national lockdown for at least 30 days were taken for the study. Patients visiting the OPD for first time, patients previously registered but did not start treatment, patients visiting for routine follow up, where adequate investigation was not feasible/available to classify present disease status, patients who had resumed their treatment at other treatment facility, patients who were lost to follow up before the pandemic situation and visited the facility during the pandemic and patients who did not provide informed consent were excluded from the study. 40 patients were selected for the study.

\section{Study Technique and Data Collection}

a. The primary characteristics of the patient and the primary disease, the treatment being delivered was recorded from the prospectively maintained patient database. Data on per capita family income and transportation cost was recorded by interviewing the patient. Distance between the treatment facility and patient's residence was calculated by noting the distance between the treatment facility and the reporting police station of the patients' residence from an online map.

b. PO BADO SF (The Basic Documentation for Psycho-Oncology Short Form)- This is a validated 6 item interview based expert rating scale for distress screening in cancer patients with a sensitivity and specificity of $75 \%$ and $82 \%$ respectively [11]. Patients were considered to be suffering from psycho social distress if they get a score of $>9$. All patients were screened using this scale during primary data collection.

c. Assessment of disease status- All patients underwent extensive physical examination to look for signs of disease progression and distant metastasis. All patient underwent either CECT (contrast enhanced computed tomography) scan, MRI (Magnetic resonance imaging) or PET CT (positron emission tomography computed tomography) whichever was applicable or available to evaluate the loco-regional disease and metastasis status. Radiological disease status was assessed according to RECIST (Response evaluation criteria in solid tumours) 1.1 criteria [12] and/or PET CT uptake, whichever was applicable.

\section{Data Analysis}

Descriptive statistics was used to evaluate the primary categorical variables. The continuous variables were evaluated by mean, standard deviation or median whichever was applicable. Associations of various categorical variables like delay response, treatment gap was evaluated by comparing various continuous data using specific non parametric tests. Association of disease progression with other categorical variables like primary site, stage, treatment gap and treatment modality was assessed using chi squared test. All data analysis was done using SPSS (Statistical package for the Social Sciences) version 23 software.

\section{Results}

The basic characteristics of the sample is described in Table 1. The median age was 50.5 years. $52.5 \%$ patients were male. Most patients were ECOG (Eastern Cooperative Oncology Group) performance status $1(82.5 \%)$. Head and neck was the most common primary site with most patient having a primary Stage III disease (42.5\%). Only $12.5 \%$ were non metastatic at presentation. Chemo radiotherapy was the most common treatment being received by the patients $(45 \%)$, followed by radiotherapy (25\%) and chemotherapy (22.5\%). 65\% patients had per capita income between INR 40000 and 80000. The mean distance between residence and hospital was $99.45 \pm 94.77 \mathrm{~km}$, with most patients (40\%) staying within $50 \mathrm{~km}$ radius, followed by $32.5 \%$ staying between 50 and $100 \mathrm{~km}$ radius. The mean cost of transportation before the pandemic was INR $366.5 \pm 580.40$, however the transportation cost increased to INR $2735 \pm 2136$. There was significant increase in cost of transportation during the pandemic (mean increase of $2368.5 \pm 1977.7$, $\mathrm{p}<0.001$, paired samples $\mathrm{t}$ test).

The median delay in visiting the treatment facility was 76.5 days, with most patient visiting after a delay of 2 months or more (95\%). Among the response given by patient and accompaints for not visiting the treatment facility, the most common was "high cost of 
Table 1. Basic Characteristics

\begin{tabular}{|c|c|c|}
\hline Characteristics & & Patients $(\%)$ \\
\hline Median age & & 50.5 years $(25-75$ years $)$ \\
\hline \multirow[t]{2}{*}{ Sex } & Male & $21(52.5)$ \\
\hline & Female & $19(47.5)$ \\
\hline \multirow[t]{3}{*}{ Co- morbidity } & Hypertension/T2DM/both & $15(37.5)$ \\
\hline & Others & $9(22.5)$ \\
\hline & No comorbidity & $16(40)$ \\
\hline \multirow[t]{4}{*}{ ECOG Performance Status at presentation } & 0 & $1(2.5)$ \\
\hline & 1 & $33(82.5)$ \\
\hline & 2 & $5(12.5)$ \\
\hline & 3 & $1(2.5)$ \\
\hline \multirow[t]{6}{*}{ Primary site } & Breast & $8(20)$ \\
\hline & Cervix & $6(15)$ \\
\hline & Head \& neck & $12(30)$ \\
\hline & Prostate & $2(5)$ \\
\hline & Lung & $11(27.5)$ \\
\hline & Others & $1(2.5)$ \\
\hline \multirow[t]{4}{*}{ Stage } & I & $2(5)$ \\
\hline & II & $10(25)$ \\
\hline & III & $17(42.5)$ \\
\hline & IV & $11(27.5)$ \\
\hline \multirow[t]{2}{*}{ Metastatic/non metastatic } & Metastatic & $5(12.5)$ \\
\hline & Non metastatic & $35(87.5)$ \\
\hline \multirow[t]{4}{*}{ Treatment being received } & Chemotherapy & $9(22.5)$ \\
\hline & Radiotherapy & $10(25)$ \\
\hline & Chemo-radiotherapy & $18(45)$ \\
\hline & Others & $3(7.5)$ \\
\hline \multirow[t]{3}{*}{ Per capita family income } & $<=40000$ & $11(27.5)$ \\
\hline & $>40000$ and $<=80000$ & $26(65)$ \\
\hline & $>80000$ & $3(7.5)$ \\
\hline \multirow{4}{*}{$\begin{array}{l}\text { Distance between home and hospital } \\
\text { (mean } 99.45 \pm 94.77 \mathrm{~km} \text { ) }\end{array}$} & $<=50 \mathrm{~km}$ & $16(40)$ \\
\hline & $>50$ and $<=100 \mathrm{~km}$ & $13(32.5)$ \\
\hline & $>100$ and $<=200 \mathrm{~km}$ & $6(15)$ \\
\hline & $>200 \mathrm{~km}$ & $5(12.5)$ \\
\hline Cost of transportation before pandemic & INR $366.5 \pm 580.40($ mean \pm SD $)$ & \\
\hline Cost of transportation during pandemic & INR $2735 \pm 2136.20($ mean \pm SD $)$ & \\
\hline
\end{tabular}

transportation" (45\%) followed by "Fear of infection with Covid 19 in hospital" (40\%). On reassessment after the delay, $50 \%$ patients had progressive disease with 6 new metastatic cases (Table 2).

Per capita family income and cost of transportation to hospital did not influence the response for delay (Table 3). The mean distance between home and treatment facility was highest in patients who responded "lack of proper accommodation" as cause of delay (p 0.564, not significant). Among the 18 patients who responded "High cost of transportation" as prime cause of delay, $85 \%$ were being treated with radiotherapy ( $\mathrm{p} 0.117$, chi squared test). $69 \%$ patients being treated with radiotherapy had responded either "lack of proper accommodation" or "high cost of transportation" as cause for delay in visiting treatment facility (p 0.065, fisher's exact test).

The factors influencing treatment gap is described in Table 4. Patients with treatment gap of 80 days or more had a significantly higher mean per capita family income and transportation cost during epidemic (p 0.024 and 0.05 respectively, Mann Whitney U test). Mean distance between home and treatment facility was higher in patients with a treatment gap of 80 days or more (not significant).

A significant association was not found between disease progression and factors like primary site and stage, treatment gap and treatment modality (Table 5).

Anxiety complained by patients for visiting a hospital treating patients infected with covid 19 was assessed as 
Table 2. Treatment Gap, Cause of Delay and Disease Status on Second Evaluation

\begin{tabular}{|c|c|c|}
\hline & & Patients $(\%)$ \\
\hline \multirow[t]{2}{*}{ Treatment gap in days } & Less than 60 days & $2(5)$ \\
\hline & More than equal to 60 days & $38(95)$ \\
\hline \multirow[t]{3}{*}{ Cause of delay } & High cost of transportation & $18(45)$ \\
\hline & Fear of infection with COVID 19 in hospital & $16(40)$ \\
\hline & Lack of proper accommodation facility & $6(15)$ \\
\hline \multirow[t]{3}{*}{ Present status of disease } & Partial response(PR) & $3(7.5)$ \\
\hline & Stable disease(SD) & $17(42.5)$ \\
\hline & Progressive disease(PD) & $20(50)$ \\
\hline \multirow[t]{2}{*}{ Metastatic status after treatment delay } & Metastatic disease & $11(27.5)$ \\
\hline & Non metastatic disease & $29(72.5)$ \\
\hline
\end{tabular}

a part of PO BADO SF questionnaire. $31(77.5 \%)$ patients had a score of $>9$ reflecting psychosocial distress in majority of the study sample.

\section{Discussion}

The COVID 19 pandemic has seriously disrupted the cancer care in the country. On one hand, the past national lockdown measure has impacted movement of patients to and from the treatment centre. An article published at Lancet oncology briefly describes the situation of cancer care due to halt in transportation facilities [8]. Various predictions said that the stagnation of patients inflow and treatment would finally lead to increased cancer burden due to patients presenting later at advanced stages of cancer [8]. A predictive modelling study predicted that $59.7 \%$ cancer surgeries were postponed during the peak 12 weeks of lockdown which would result in adding to the cancer burden at a later stage [13]. In our study, we used disease progression due to gap in treatment according to RECIST criteria [12] as an indirect evidence towards increased cancer burden. Disease progression may lead to hampering of curative intent treatment, require more aggressive therapy which would indirectly contribute to increased cancer burden. In our study $50 \%$ of the patients had disease progression during study evaluation with $15 \%$ (6 patients) progression to distant metastasis (Table 2).
Patients with head neck/lung primary had progression in $56.5 \%(13 / 23)$ whereas patients with other primary site had progression in $41.18 \%(7 / 17)$ patients, however the association was not significant. More progression in head neck or lung primary may be due to high tumour doubling time in these sites. A study by Bhattacharjee et al has given an analytical strategy of disease progression based on time dependent modelling during the covid pandemic [14]. However, actual clinical data is limited in the present literature.

Among the response to cause of delay in visiting treatment facility, most patients had responded "high cost of transportation" (45\%). This is on a par with significantly increased overall cost of transportation during the pandemic (Table $1, \mathrm{p}<0.001$ ). However, the increased cost of transportation was non-significant across all treatment groups (Table 3). 69\% patients being treated with radiotherapy had responded either "high cost of transportation" or "lack of proper accommodation facility" which was close to significant (Fisher's exact test, $\mathrm{p}<0.065$ ). A reason for this response maybe due to almost regular visits in the department for treatment with radiotherapy compared to other modalities ultimately adding to the treatment cost.

Patients with larger treatment gap had significantly high cost of transportation during the national lockdown (Table 4). Patients with larger treatment gap also had

Table 3. Association between Various Delay Response and Other Variables

\begin{tabular}{|c|c|c|c|c|}
\hline & High cost of transportation & Fear of infection with COVID 19 & Lack of proper accommodation & $P$ value \\
\hline Per capita income & INR $54000 \pm 21359.66$ & INR $68625 \pm 64637$ & INR $45333 \pm 11430$ & 0.56 \\
\hline $\begin{array}{l}\text { Cost of transportation during } \\
\text { the pandemic }\end{array}$ & INR $2927 \pm 2892$ & INR $2406 \pm 1175$ & INR $3033 \pm 1555$ & 0.718 \\
\hline Distance from treatment centre & $95.05 \pm 98.06 \mathrm{~km}$ & $83.5 \pm 78 \mathrm{~km}$ & $155.16 \pm 120.43 \mathrm{~km}$ & 0.564 \\
\hline Treatment with radiotherapy & $15(83.3 \%)$ & $9(56.3 \%)$ & $5(83.3 \%)$ & 0.117 \\
\hline
\end{tabular}

Table 4. Factors Associated with Gap in Treatment

\begin{tabular}{lccc}
\hline & $\begin{array}{c}\text { Treatment gap less } \\
\text { than 80 days }\end{array}$ & $\begin{array}{c}\text { Treatment gap of } \\
80 \text { days or more }\end{array}$ & $\begin{array}{c}\text { P value } \\
\text { (Mann Whitney U test) }\end{array}$ \\
\hline Per capita income & INR 55680 \pm 52062.24 & INR 63333.33 \pm 24674.06 & 0.024 \\
Cost of transportation during the pandemic & INR 2020 \pm 1187.08 & INR $3760 \pm 2914$ & 0.05 \\
Distance from treatment centre & $83.44 \pm 73.70 \mathrm{~km}$ & $126.13 \pm 120.36 \mathrm{~km}$ & 0.201 \\
\hline
\end{tabular}


Table 5. Association of Disease Progression with other Variables

\begin{tabular}{|c|c|c|c|c|}
\hline & & Progressive disease [20] & Stable disease /Partial response [20] & $\mathrm{P}$ value \\
\hline \multirow[t]{2}{*}{ Treatment gap } & Less than 80 days & $11(55 \%)$ & $14(70 \%)$ & 0.327 \\
\hline & More than equal to 80 days & $9(45 \%)$ & $6(30 \%)$ & \\
\hline \multirow[t]{4}{*}{ Stage at diagnosis } & Stage I & $2(10 \%)$ & 0 & 0.214 \\
\hline & Stage II & $3(15 \%)$ & $7(35 \%)$ & \\
\hline & Stage III & $8(40 \%)$ & $9(45 \%)$ & \\
\hline & Stage IV & $7(35 \%)$ & $4(20 \%)$ & \\
\hline \multirow[t]{2}{*}{ Treatment modality used } & Treatment with RT & $15(75 \%)$ & $14(70 \%)$ & 0.72 \\
\hline & Treatment with other modality & $5(25 \%)$ & $6(30 \%)$ & \\
\hline \multirow[t]{2}{*}{ Primary site } & Head neck/ Lung primary & $13(65 \%)$ & $10(50 \%)$ & 0.337 \\
\hline & Other primary & $7(35 \%)$ & $10(50 \%)$ & \\
\hline
\end{tabular}

larger distance between home and treatment facility (not significant). However, patients with larger treatment gap also had significantly higher per capita family income, which cannot be explained with the available data. Probably other socio economic factors like education, geographical location etc. has played part in decision making which was not part of the study protocol.

$77.5 \%$ of the study sample had reported psycho social distress for visiting the hospital treating patients infected with SARS-COV 2. In a study published by G Chen et al on psychological stress in cancer patients during the pandemic, $67.5 \%$ patients had anxiety $74.5 \%$ patients had depression [15].

Finally, various measures were taken by institutes treating cancer patients to optimize treatment in the pandemic situation. Among them, some were tele-consultation, using short course radiotherapy to decrease hospital visits, delay treatment if possible, conducting distance screening camps outside hospital etc [9-16]. Such measures could not be implemented in our institute due to a number of hassles. Our institute is dedicated to the treatment of covid 19 patients, thus a major manpower is diverted to the cause leading to shortage of manpower in the department. The measures that were taken were primary screening of patients for covid 19 infection to reduce infection spread among patients and health care providers, shorter course of radiotherapy if feasible and early referrals for chemotherapies at local government health centres. With the ease of lockdown measures, the influx of patients have increased considerably at the present date, although the numbers are far less than before the pandemic.

In conclusion, COVID 19 pandemic control measures have impacted cancer care in resulting in disease progression, treatment delays and psycho-social distress. A number of factors may have contributed to the treatment delays like high cost of transportation during the lockdown, longer distance between residence and hospital. Psychosocial distress may be a result of anxiety of visiting the treatment facility caring for covid patients.

Some measures have been taken to mitigate the issues like early referrals and using of shorter courses of radiotherapy wherever applicable. With normalization of hospital attendance in the present days, a comprehensive protocol is required to provide adequate care and simultaneously reduce risk of transmission of infection.

\section{References}

1. WHO Director-General's opening remarks at the media briefing on COVID-19 - 11 March 2020 [Internet]. [cited 2020 Jul 15]. Available from: https://www.who.int/dg/ speeches/detail/who-director-general-s-opening-remarks-atthe-media-briefing-on-covid-19---11-march-2020..

2. World Bank says coronavirus outbreak may take heavy toll on Asia's economy - MarketWatch [Internet]. [cited $2020 \mathrm{Jul}$ 16]. Available from: https://www.marketwatch.com/story/ world-bank-says-coronavirus-outbreak-may-take-heavytoll-on-asias-economy-2020-03-30.

3. The current state of Latin America's economy [Internet]. Dialogo Chino. 2020 [cited 2020 Jul 16]. Available from: https://dialogochino.net/en/trade-investment/34547coronavirus-takes-toll-on-latin-american-economies/.

4. Govt will focus on both health of economy and people as coronavirus takes toll, says PM Modi - The Financial Express [Internet]. [cited 2020 Jul 16]. Available from: https://www. financialexpress.com/economy/govt-will-focus-on-bothhealth-of-economy-and-people-as-coronavirus-takes-tollsays-pm-modi/2018885/.

5. India Situation Report [Internet]. [cited 2020 Jul 16]. Available from: https://www.who.int/india/emergencies/coronavirusdisease-(covid-19)/india-situation-report.

6. Dar M, Sharma K. Burden of cancer in India: GLOBOCAN 2018 Estimates Incidence, Mortality, prevalence and future projections of cancer in India”. 2019 Jun 16;:505-14.

7. Bray F, Ferlay J, Soerjomataram I, Siegel RL, Torre LA, Jemal A. Global cancer statistics 2018: GLOBOCAN estimates of incidence and mortality worldwide for 36 cancers in 185 countries. CA: A Cancer Journal for Clinicians. 2018 09 12;68(6):394-424. https://doi.org/10.3322/caac.21492

8. Sharma DC. Lockdown poses new challenges for cancer care in India. The Lancet Oncology. 2020 07;21(7):884. https:// doi.org/10.1016/s1470-2045(20)30312-0

9. Sundriyal D, Sehrawat A, Kumar P, Bhandari R. Impact of COVID-19 pandemic on oncology practices during nationwide lockdown period: a single centre experience and the way forward. The Journal of the Association of Physicians of India. 2020 Jul 1;68(7):50.

10. González Ferreira JA, Jaén Olasolo J, Azinovic I, Jeremic B. Effect of radiotherapy delay in overall treatment time on local control and survival in head and neck cancer: Review of the literature. Reports of Practical Oncology 
\& Radiotherapy. 2015 09;20(5):328-339. https://doi. org/10.1016/j.rpor.2015.05.010

11. Marten-Mittag B, Book K, Buchhold B, Dinkel A, Gründobler B, Henrich G, Huber B, Pirker C, Regenberg A, Schickel S, Senf B, Wünsch A, Herschbach P. The Basic Documentation for Psycho-Oncology Short Form (PO-Bado SF)-an expert rating scale for distress screening: development and psychometric properties. Psycho-Oncology. 2014 Oct 24;24(6):653-660. https://doi.org/10.1002/pon.3708

12. Schwartz LH, Litière S, de Vries E, Ford R, Gwyther S, Mandrekar S, Shankar L, Bogaerts J, Chen A, Dancey J, Hayes W, Hodi FS, Hoekstra OS, Huang EP, Lin N, Liu Y, Therasse P, Wolchok JD, Seymour L. RECIST 1.1Update and clarification: From the RECIST committee. European Journal of Cancer. 2016 07;62:132-137. https:// doi.org/10.1016/j.ejca.2016.03.081

13. . Elective surgery cancellations due to the COVID-19 pandemic: global predictive modelling to inform surgical recovery plans. British Journal of Surgery. 202006 13; https://doi.org/10.1002/bjs.11746

14. Bhattacharjee A, Vishwakarma GK, Banerjee S, Shukla S. Disease progression of cancer patients during COVID-19 pandemic: a comprehensive analytical strategy by timedependent modelling. BMC Medical Research Methodology. 202008 12;20(1). https://doi.org/10.1186/s12874-02001090-z

15. Chen $\mathrm{G}$, Wu Q, Jiang H, Zhang H, Peng J, Hu J, Chen M, Zhong Y, Xie C. Fear of disease progression and psychological stress in cancer patients under the outbreak of COVID -19. Psycho-Oncology. 202007 14;29(9):13951398. https://doi.org/10.1002/pon.5451

16. Pramesh C, Badwe RA. Cancer Management in India during Covid-19. New England Journal of Medicine. 2020 05 14;382(20):e61. https://doi.org/10.1056/nejmc2011595

This work is licensed under a Creative Commons AttributionNon Commercial 4.0 International License. 